\title{
MENINGKATKAN HASIL BELAJAR SISWA TENTANG MEMBACA NYARING DENGAN METODE DEMONSTRASI
}

\author{
Karlina \\ SDN 44 Lubuklinggau \\ karlina2018@gmail.com
}

\begin{abstract}
ABSTRAK
Tujuan penelitian ini adalah untuk meningkatkan hasil belajar Bahasa Indonesia tentang membaca nyaring dengan menggunakan metode demonstrasi, siswa kelas III A SD Negeri 44 Lubuklinggau. Rencana tindakan yang akan dilakukan untuk meningkatkan kemampuan membaca nyaring dan membaca dongeng. Penelitian tindakan ini dilaksanakan 2 siklus, siklus 1 terdiri dari 1 pertemuan dan siklus 2 terdiri dari 1 pertemuan. Siklus 1 dan 2 menggunakan metode demonstrasi. Hasil penelitian, pada siklus pertama, siswa hanya aktif berdiskuasi dengan teman hanya 3 orang dari tiap kelompok atau sekitar $37,50 \%$, tetapi pada siklus kedua ada kenaikan sehingga rata-rata tiap kelompok yang aktif berdiskusi ada 6 orang tiap kelompok. Sedangkan kenaikan yang cukup signifikan terjadi pada keaktifan siswa dalam menjawab soal-soal yang diberikan dari 3 orang atau 37,50\% pada siklus pertama menjadi $56,67 \%$. Simpulan, pembelajaran bahasa Indonesia tentang membaca nyaring dengan menggunakan metode demontrasi dapat meningkatkan hasil belajar siswa.
\end{abstract}

Kata Kunci: Hasil Belajar, Metode Demonstrasi, Membaca Nyaring

\begin{abstract}
The study aims at improving Bahasa Indonesia learning achievement in reading aloud by using demonstration method. The subject was the students of grade III A at SD Negeri 44 Lubuklinggau. The plan of action was to improve the skill in reading aloud and reading fairy tale. The research was conducted in two cycles, namely cycle 1 and cycle 2 by using demonstration method. The result was, in cycle I, the students who were active in having the discussion to friends were only 3 students in each group or around 37,50\%. In contrast, in cycle II there was an improvement in each group. There were 6 students who did the discussion in each group. The significant improvement happened when they answered the questions. There were 3 students or 37,50\% that showed the improvement in cycle I to $56,67 \%$. In summary, teaching reading aloud by using demonstration method can improve students achievement.
\end{abstract}

Keywords: Achievement, Demonstration Method, Reading Aloud 


\section{PENDAHULUAN}

Guru adalah pendidik profesional yang memiliki tugas mulia, yaitu sebagai agen perubahan (Wina, 2006). Oleh karena itu, dalam rangka pelaksanaan tugasnya, guru dituntut untuk selalu inovatif dalam mengemas kegiatan pembelajaran yang dilakukannya, sehingga terbentuk suasana pembelajaran yang interaktif, inspiratif, menyenangkan memotivasi peserta didik untuk berpartisipasi aktif, terbangunnya kemampuan berprakarsa, berkembangnya kreatifitas dan kemandirian peserta didik sesuai dengan bakat, minat, serta perkembangan fisik dan psikologis peserta didik.

Pada dasarnya keterampilan membaca dan menulis sangat memegang peranan penting dalam kehidupan manusia, karena pengetahuan apapun tidak terlepas dari membaca dan menulis (Syafei, 2003). Tanpa memiliki ketrampilan tersebut, maka pengetahuan apapun yang diberikan akan sia-sia dan tidak berarti, mengingat saat ini merupakan era globalisasi yang banyak menuntut berbagai ketrampilan.

Oleh sebab itu, penguasaan ketrampilan membaca dan menulis sangat diperlukan. Pengajaran membaca dan menulis pada sekolah dasar merupakan salah satu bidang garapan yang memegang peranan penting dalam pengajaran Bahasa Indonesia (Zuchdi, 1997), karena tanpa memiliki pengetahuan dan ketrampilan membaca dan menulis maka akan mengalami kesulitan belajar di masa mendatang atau tingkat sekolah lanjutnya. Keterampilan membaca dan menulis menjadi dasar utama, tidak hanya bagi bidang pengajaran bahasa, tetapi bidang pengajaran lainnya, seperti PKn, Matematika, IPA, IPS, dan lain-lain.

Dengan membaca dan menulis, siswa akan memperoleh pengetahuan yang sangat bermanfaat bagi pertumbuhan dan perkembangan sosial, daya nalar dan emosionalnya (Sumardi, 1992). Melalui pendidikan formal, siswa banyak belajar membaca dan menulis.Pendidikan formal harus dapat banyak memberikan latihan-latihan kepada siswa untuk melatih keterampilan berpikir (Sabarti, 1996).

Kebiasaan membaca tidak mungkin terlaksana tanpa kebiasaan menulis, sebaliknya kebiasaan menulis tidak akan bermakna tanpa kegiatan membaca (Tampubolon, 1990). Minat membaca dan menulis peserta didik relatif menurun dikarenakan efek globalisasi yang menyita perhatian dengan banyaknya tayangan informasi dan hiburan dari dunia maya. Keberhasilan suatu proses pembelajaran dapat dilihat dari hasil belajar siswa. Berdasarkan hasil belajar siswa kelas III A SD Negeri 44 semester I Tahun Pelajaran 2016/2017 masih rendah khususnya Bahasa Indonesia. Ini dapat dilihat dari hasil evaluasi belajar pra siklus 66,66\% dari jumlah siswa, memperoleh nilai dibawah KKM 75 dan hasil rata-rata kelas 72,56. Untuk meningkatkan hasil belajar diperlukan penggunaan metode demonstrasi, untuk memudahkan siswa memahami materi yang disampaikan. 


\section{METODE PENELITIAN}

Rencana tindakan yang akan dilakukan untuk meningkatkan kemampuan membaca nyaring dan membaca dongeng. Penelitian tindakan ini dilaksanakan 2 siklus, siklus 1 terdiri dari 1 pertemuan dan siklus 2 terdiri dari 1 pertemuan. Siklus 1 dan 2 menggunakan metode demonstrasi.Setiap siklus terdiri dari

\section{Siklus 1}

1. Perencanaan. Peneliti perlu membuat perencanaan sebelum melakukan tindakan sebagai berikut: (a) menyiapkan instrumen penelitian berupa lembar observasi, (b) menyiapkan materi ajar berupa buku Bahasa Indonesia Kelas III, (c) menyusun Rencana Pelaksanaan Pembelajaran (RPP).

2. Tindakan/Pelaksanaan. Peneliti melakukan apersepsi sebagai langkah awal. Kemudian menyampaikan tujuan yang akan dicapai dalam pembelajaran sesuai dengan RPP yang dibuat. Penulis mengajarkan bagaimana membaca nyaring dengan lafal dan intonasi yang tepat. Selanjutnya siswa mengerjakan tugas. Langkah berikutnya berkeliling untuk mengobservasi, mengevaluasi dan sekaligus membimbing siswa.

3. Observasi. Peneliti dibantu observer mengamati jalannya proses pembelajaran dan menilai siswa dalam bekerja. Kemudian manganalisa data siklus 1 dari hasil observasi yang dilakukan.

4. Refleksi. Dilakukan untuk memahami hal-hal yang berkaitan dengan proses dan hasil yang diperoleh dari tindakan yang telah dilakukan. Melakukan analisa berupa temuan-temuan yang berupa hambatan, kekurangan dan kelemahan yang dijumpai selama siklus 1 sebagai masukan untuk siklus 2 .

\section{Siklus 2}

1. Perencanaan. Peneliti mengidentifikasi data dan informasi dari hasil refleksi dan pengamatan observasi pada siklus 1 kemudian menyusun Rencana Pelaksanaan Pembelajaran (RPP) mata pelajaran Bahasa Indonesia pokok bahasan membaca nyaring.

2. Tindakan/Pelaksanaan. Peneliti melakukan apersepsi pada materi yang terkait sebagai langkah awal untuk mengetahui kemampuan awal siswa. Kemudian menyampaikan tujuan yang akan dicapai dalam pembelajaran sesuai dengan RPP yang dibuat.

3. Observasi. Peneliti dibantu observer mengamati jalannya proses pembelajaran dan menilai siswa dalam bekerja dan menyajikan hasil kerja individu. Kemudian manganalisis data siklus 2 dari hasil observasi yang dilakukan dengan lembar observasi.

4. Refleksi. Dilakukan untuk memahami hal-hal yang berkaitan dengan proses dan hasil yang diperoleh dari tindakan siklus 2 yang telah dilakukan. Kemudian melakukan pengumpulan data berdasarkan hasil kegiatan 
pembelajaran pada siklus 2 sebagai bahan data informasi dalam pengolahan data, analisis serta penafsiran data.

\section{HASIL PENELITIAN}

Sebelum melaksanakan siklus pertama, siswa diberi lembar test guna mengetahui kondisi kemampuan siswa dalam memahami konsep bahasa Indonesia tentang mendeskripsikan gambar. Hasil penilaian selengkapnya dapat kita lihat pada tabel di bawah ini :

Tabel 1.

Skor Hasil Belajar Siswa Siklus Awal

\begin{tabular}{|c|c|c|c|c|}
\hline \multicolumn{2}{|l|}{ No } & \multirow{2}{*}{ Nama Siswa } & \multirow{2}{*}{ Tes Awal } & \multirow{2}{*}{ Keterangan } \\
\hline Urt & $\mathbf{P} / \mathbf{L}$ & & & \\
\hline 1. & $\mathrm{P}$ & Aisyah Listiana & 80 & Tuntas \\
\hline 2. & $\mathrm{~L}$ & Budi Santoso & 45 & Belum Tuntas \\
\hline 3. & $\mathrm{P}$ & Bella Rahmania & 80 & Tuntas \\
\hline 4. & $\mathrm{P}$ & Carisa Loventa & 50 & Belum Tuntas \\
\hline 5. & $\mathrm{P}$ & Cherty Megyansari & 30 & Belum Tuntas \\
\hline 6. & $\mathrm{P}$ & Fani Venezia & 40 & Belum Tuntas \\
\hline 7. & $\mathrm{~L}$ & Fino Rama Saputra & 90 & Tuntas \\
\hline 8. & $\mathrm{~L}$ & Galih Amdi. M & 30 & Belum Tuntas \\
\hline 9. & $\mathrm{P}$ & Diah Putri & 78 & Tuntas \\
\hline 10. & $\mathrm{P}$ & Kayla Putri & 12 & Belum Tuntas \\
\hline 11. & $\mathrm{P}$ & Laviola Froren & 85 & Tuntas \\
\hline 12. & $\mathrm{~L}$ & M. Rehan & 30 & Belum Tuntas \\
\hline 13. & $\mathrm{~L}$ & Muhammad Dimas & 11 & Belum Tuntas \\
\hline 14. & $\mathrm{P}$ & Nabilah Raidah & 65 & Tuntas \\
\hline 15. & $\mathrm{P}$ & Rahma Cahya & 10 & Belum Tuntas \\
\hline 16. & $\mathrm{~L}$ & Teguh Praworo & 80 & Tuntas \\
\hline 17. & $\mathrm{~L}$ & Theo Danendra & 12 & Belum Tuntas \\
\hline 18. & $\mathrm{~L}$ & Viky Parel & 32 & Belum Tuntas \\
\hline 19. & $\mathrm{P}$ & Zhakyla & 75 & Tuntas \\
\hline 20. & $\mathrm{P}$ & Almas Nur Alifah & 75 & Tuntas \\
\hline 21. & $\mathrm{~L}$ & Dwilas & 90 & Tuntas \\
\hline 22. & $\mathrm{P}$ & Krisnawati & 75 & Tuntas \\
\hline 23. & $\mathrm{P}$ & Nisrina & 75 & Tuntas \\
\hline 24. & $\mathrm{P}$ & Rheyna & 74 & Tuntas \\
\hline 25. & $\mathrm{~L}$ & M. Syafrial & 70 & Tuntas \\
\hline 26. & $\mathrm{~L}$ & Bagus Hobert & 70 & Tuntas \\
\hline 27 & $\mathrm{~L}$ & Irwansyah & 30 & Belum Tuntas \\
\hline 28 & $\mathrm{~L}$ & M. Yusuf & 11 & Belum Tuntas \\
\hline 29 & $\mathrm{P}$ & Suci Gusti & 75 & Tuntas \\
\hline 30 & $\mathrm{~L}$ & M. Firmansyah & 75 & Tuntas \\
\hline \multicolumn{3}{|c|}{ Jumlah } & \multicolumn{2}{|l|}{1583} \\
\hline \multicolumn{3}{|c|}{ Rata-rata } & \multicolumn{2}{|l|}{51,32} \\
\hline
\end{tabular}


Berdasarkan data perolehan nilai di atas maka diketahui bahwa sebanyak 11 siswa atau 66,66\% memperoleh nilai diatas SKBM/Batas Ketuntasan Belajar Minimal. Dapat disimpulkan bahwa sebagian besar siswa belum memahami konsep Bahasa Indonesia tentang mendiskripsikan benda tersebut, maka perlu diadakan perbaikan melalui program remedial. Program ini dilaksanakan di luar jam pelajaran yang ada dalam bentuk kelompok-kelompok kecil. Peneliti hanya mengamati proses remedial. Dalam pembuatan rencana tindakan dalam siklus pertama mengacu pada hasil tes tersebut. Pada akhir siklus ini akan di test kembali agar siswa dapat memperbaiki nilainya dan mencapai ketuntasan belajar minimalnya.

\section{Siklus I}

Perencanaan pengajaran pada Siklus I ini terdiri dari 1 tahap perencanaan pengajaran yang ditetapkan pada pertemuan kesatu. Secara garis besar perencanaan pengajaran yang ditetapkan pada dasarnya sama dengan perencanaan umum. Adapun perbedaan dapat diungkapkan di bawah ini.

Perencanaan pembelajaran siklus I difokuskan pada remidi pada mendiskripsikan benda. Perencanaan pada siklus I ini, penulis deskripsikan bahwa Kegiatan Pendahuluan meliputi: (a) motivasi dan apersepsi, (b) guru memberikan pertanyaan mengenai pelajaran yang telah lalu yang telah dipelajari sebelumnya, (c) guru mengaitkan pelajaran yang lalu dengan yang akan dipelajari, dengan menanyakan mengapa benda-benda/gambar benda-benda atau alat-alat yang ada pada gambar dapat bermanfaat?, (d) guru menyampaikan indikator hasil yang akan dicapai dalam belajar. Kegiatan Inti meliputi; (a) siswa dibagi menjadi 3 kelompok, setiap kelompok terdiri 8-9 orang secara acak. Setiap kelompok mendapatkan satu lembar gambar yang akan dipelajari, dengan judul gambar "Menonton Pertunjukan Sulap", (b) guru memberikan dorongan agar siswa aktif melakukan pengamatan, (c) siswa melakukan diskusi kolompok dan menyiapkan kesimpulan hasil pengamatan untuk disajikan pada diskusi kelas, (d) setiap kelompok diberi kesempatan untuk menyajikan hasil pengamatan yang diwakili oleh salah seorang anggota, dan kelompok lain ikut serta mengamati dan mengevaluasi hasil yang disampaikan, (e) guru memberikan bimbingan kepada siswa untuk menuliskan kebaikan dan kelemahan serta kegunaan bendabenda/gambar benda-benda atau alat-alat yang ada pada gambar yang dapat bermanfaat, (f) dengan bimbingan guru, siswa bersama-sama menyimpulkan materi pelajaran, (g) guru mengadakan refleksi, untuk mengetahui berhasil tidaknya kegiatan remedial yang dilakukan oleh tutor sebaya, sebagai tes siklus kedua. Kegiatan Penutup meliputi; (a) siswa mendapat kesempatan mencatat kesimpulan, (b) siswa dan guru bersama-sama mengintegrasikan materi tentang kebaikan dan kelemahanya serta kegunaan benda-benda/gambar benda-benda atau alat-alat yang ada pada gambar yang dapat bermanfaat, (c) siswa menjawab tes secara tertulis pilihan ganda sebagai tes siklus pertama. 
Tabel 2

Skor Hasil Belajar Siswa Siklus I

\begin{tabular}{|c|c|c|c|c|}
\hline \multicolumn{2}{|l|}{ No } & \multirow{2}{*}{ Nama Siswa } & \multirow{2}{*}{ Tes Awal } & \multirow{2}{*}{ Keterangan } \\
\hline Urt & Induk & & & \\
\hline 1. & $\mathrm{P}$ & Aisyah Listiana & 80 & Tuntas \\
\hline 2. & $\mathrm{~L}$ & Budi Santoso & 80 & Tuntas \\
\hline 3. & $\mathrm{P}$ & Bella Rahmania & 80 & Tuntas \\
\hline 4. & $\mathrm{P}$ & Carisa Loventa & 80 & Tuntas \\
\hline 5. & $\mathrm{P}$ & Cherty Megyansari & 30 & Belum Tuntas \\
\hline 6. & $\mathrm{P}$ & Fani Venezia & 40 & Belum Tuntas \\
\hline 7. & $\mathrm{~L}$ & Fino Rama Saputra & 90 & Tuntas \\
\hline 8. & $\mathrm{~L}$ & Galih Amdi. M & 80 & Tuntas \\
\hline 9. & $\mathrm{P}$ & Diah Putri & 78 & Tuntas \\
\hline 10. & $\mathrm{P}$ & Kayla Putri & 12 & Belum Tuntas \\
\hline 11. & $\mathrm{P}$ & Laviola Froren & 85 & Tuntas \\
\hline 12. & $\mathrm{~L}$ & M. Rehan & 30 & Belum Tuntas \\
\hline 13. & $\mathrm{~L}$ & Muhammad Dimas & 80 & Tuntas \\
\hline 14. & $\mathrm{P}$ & Nabilah Raidah & 65 & Tuntas \\
\hline 15. & $\mathrm{P}$ & Rahma Cahya & 10 & Belum Tuntas \\
\hline 16. & $\mathrm{~L}$ & Teguh Praworo & 80 & Tuntas \\
\hline 17. & $\mathrm{~L}$ & Theo Danendra & 12 & Belum Tuntas \\
\hline 18. & $\mathrm{~L}$ & Viky Parel & 32 & Belum Tuntas \\
\hline 19. & $\mathrm{P}$ & Zhakyla & 75 & Tuntas \\
\hline 20. & $\mathrm{P}$ & Almas Nur Alifah & 75 & Tuntas \\
\hline 21. & $\mathrm{~L}$ & Dwilas & 90 & Tuntas \\
\hline 22. & $\mathrm{P}$ & Krisnawati & 75 & Tuntas \\
\hline 23. & $\mathrm{P}$ & Nisrina & 75 & Tuntas \\
\hline 24. & $\mathrm{P}$ & Rheyna & 74 & Tuntas \\
\hline 25. & $\mathrm{~L}$ & M. Syafrial & 70 & Tuntas \\
\hline 26. & $\mathrm{~L}$ & Bagus Hobert & 70 & Tuntas \\
\hline 27. & $\mathrm{~L}$ & Irwansyah & 30 & Belum Tuntas \\
\hline 28. & $\mathrm{~L}$ & M. Yusuf & 80 & Tuntas \\
\hline 29. & $\mathrm{P}$ & Suci Gusti & 75 & Tuntas \\
\hline \multirow[t]{3}{*}{30.} & $\mathrm{~L}$ & M. Firmansyah & 75 & Tuntas \\
\hline & \multicolumn{2}{|l|}{ Jumlah } & \multicolumn{2}{|l|}{1583} \\
\hline & \multicolumn{2}{|l|}{ Rata-rata } & \multicolumn{2}{|l|}{51,32} \\
\hline
\end{tabular}

Berdasarkan data perolehan nilai di atas maka diketaui bahwa sebanyak 12 siswa atau 48,00\% sudah memperoleh nilai di atas SKBM/Batas Ketuntasan Belajar Minimal dan sebagian besar siswa masih belum memahami konsep Bahasa Indonesia tentang mendiskripsikan benda tersebut, maka perlu diadakan perbaikan.

\section{Siklus II}

Dalam siklus II tindakan kelas yang dilakukan sebagai berikut. Berdasarkan hasil refleksi diketahui bahwa sebagian besar siswa masih belum 
memahami konsep Bahasa Indonesia tentang mendiskripsikan benda. Hal itu ditunjukkan dengan hasil tes siklus I. Oleh sebab itu peneliti melakukan remidi kembali untuk memperjelas materi yang di ajarkan, langkah-langkah peneliti dalam melakuakn remidi akan di uraikan dari Kegiatan Pendahuluan meliputi; (a) motivasi dan apersepsi, (b) guru memberikan pertanyaan mengenai pelajaran yang telah lalu yang telah dipelajari sebelumnya, (c) guru mengaitkan pelajaran yang lalu dengan yang akan dipelajari, dengan menanyakan mengapa bendabenda/gambar benda-benda atau alat-alat yang ada pada gambar dapat bermanfaat?, (d) guru menyampaikan indikator hasil yang akan dicapai dalam belajar. Kegiatan Inti meliputi; (a) siswa dibagi menjadi 3 kelompok, setiap kelompok terdiri 8-9 orang secara acak. Setiap kelompak mendapatkan satu lembar gambar yang akan dipelajari, dengan judul gambar "Ronda Malam", (b) guru memberikan dorongan agar siswa aktif melakukan pengamatan, (c) siswa melakukan diskusi kelompok dan menyiapkan kesimpulan hasil pengamatan untuk disajikan pada diskusi kelas, (d) setiap kelompak diberi kesempatan untuk menyajikan hasil pengamatan yang diwakili oleh salah seorang anggota, dan kelompok lain ikut serta mengamati dan mengevaluasi hasil yang disampaikan, (e) guru memberikan bimbingan kepada siswa untuk menuliskan kebaikan dan kelemahan serta kegunaan benda-benda/gambar benda-benda atau alat-alat yang ada pada gambar yang dapat bermanfaat, (f) dengan bimbingan guru, siswa bersama-sama menyimpulkan materi pelajaran, (g) guru mengadakan refleksi, untuk mengetahui berhasil tidaknya kegiatan remedial yang dilakukan oleh tutor sebaya sebagai tes siklus II. Kegiatan Penutup meliputi; (a) siswa mendapat kesempatan mencatan kesimpulan, (b) siswa dan guru bersama-sama mengintegrasikan materi tentang kebaikan dan kelemahan serta kegunaan bendabenda/gambar benda-benda atau alat-alat yang ada pada gambar yang dapat bermanfaat, (c) setelah selesai dilaksanakan pengintegrasian materi tentang kebaikan dan kelemahan serta kegunaan benda-benda/gambar benda-benda atau alat-alat yang ada pada gambar yang dapat bermanfaat, maka dilaksanakan test kembali untuk mengetahui tingkat keberhasilannya.

Tabel 3

Skor Hasil Belajar Siswa Siklus I

\begin{tabular}{lllll}
\hline No & & Nama Siswa & Tes Awal & Keterangan \\
\cline { 1 - 2 } Urt & Induk & & & \\
\hline 1. & P & Aisyah Listiana & 85 & Tuntas \\
\hline 2. & L & Budi Santoso & 80 & Tuntas \\
\hline 3. & P & Bella Rahmania & 85 & Tuntas \\
\hline 4. & P & Carisa Loventa & 85 & Tuntas \\
\hline 5. & P & Cherty Megyansari & 90 & Tuntas \\
\hline 6. & P & Fani Venezia & 95 & Tuntas \\
\hline 7. & L & Fino Rama Saputra & 90 & Tuntas \\
\hline 8. & L & Galih Amdi. M & 80 & Tuntas \\
\hline
\end{tabular}




\begin{tabular}{lllll}
\hline 9. & P & Diah Putri & 85 & Tuntas \\
\hline 10. & P & Kayla Putri & 90 & Tuntas \\
\hline 11. & P & Laviola Froren & 85 & Tuntas \\
\hline 12. & L & M. Rehan & 90 & Tuntas \\
\hline 13. & L & Muhammad Dimas & 80 & Tuntas \\
\hline 14. & P & Nabilah Raidah & 65 & Tuntas \\
\hline 15. & P & Rahma Cahya & 90 & Tuntas \\
\hline 16. & L & Teguh Praworo & 80 & Tuntas \\
\hline 17. & L & Theo Danendra & 90 & Tuntas \\
\hline 18. & L & Viky Parel & 90 & Tuntas \\
\hline 19. & P & Zhakyla & 75 & Tuntas \\
\hline 20. & P & Almas Nur Alifah & 75 & Tuntas \\
\hline 21. & L & Dwilas & 90 & Tuntas \\
\hline 22. & P & Krisnawati & 75 & Tuntas \\
\hline 23. & P & Nisrina & 75 & Tuntas \\
\hline 24. & P & Rheyna & 74 & Tuntas \\
\hline 25. & L & M. Syafrial & 70 & Tuntas \\
\hline 26. & L & Bagus Hobert & 70 & Tuntas \\
\hline 27. & L & Irwansyah & 90 & Tuntas \\
\hline 28. & L & M. Yusuf & $\mathbf{5 1 , 3 2}$ & Tuntas \\
\hline 29. & P & Suci Gusti & 75 & Tuntas \\
\hline 30. & L & M. Firmansyah & 75 & Tuntas \\
\hline & Jumlah & & & \\
\hline & Rata-rata & & 90 & \\
\hline & & & 90 & \\
\hline
\end{tabular}

Dari hasil nilai ulangan pada siklus II menunjukan rata-rata nilainya 74,40 dan prosentase ketuntasa belajar siswa mencapai $88,00 \%$ itu artinya sudah melebihi batas kelulusan yang ditentukan. Dari hasil analisis dan refleksi, dapat dievaluasi tindakan yang diterapkan guru ini cukup berhasil. Mengingat adanya konsistensi peningkatan nilai secara individual maupun rata-rata klasikal, maka tindakan kelas berupa program remidi dinilai berhasil dan dihentikan.

Tabel 4.

\section{Pengamatan Tingkah laku Siswa dalam Sekolah}

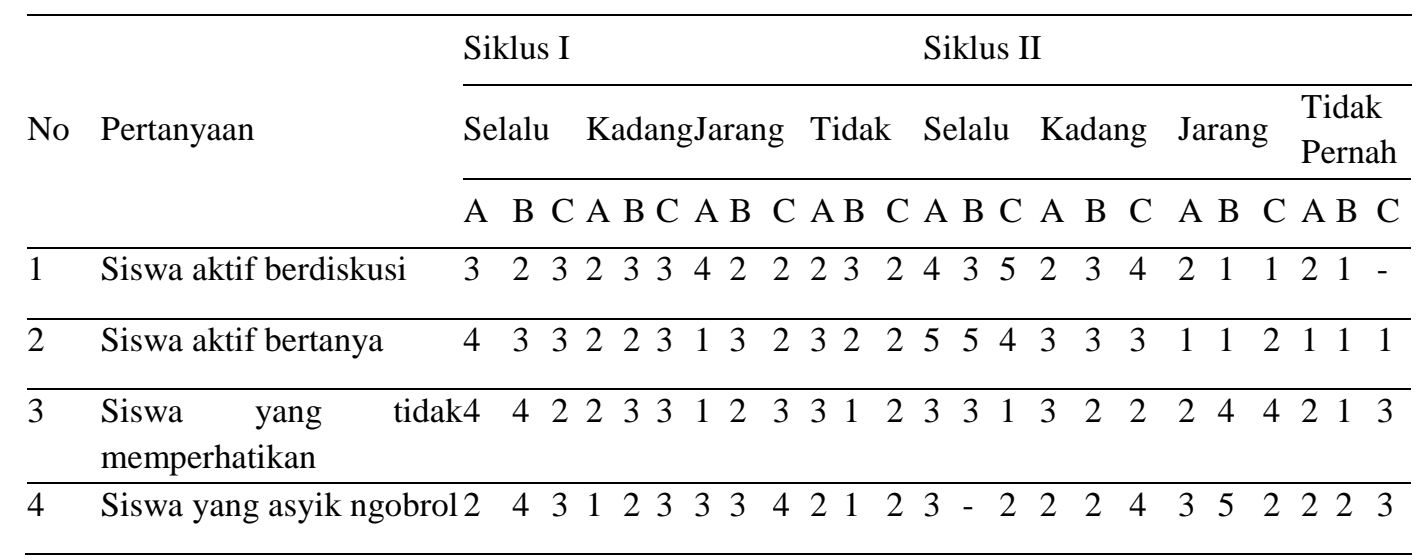



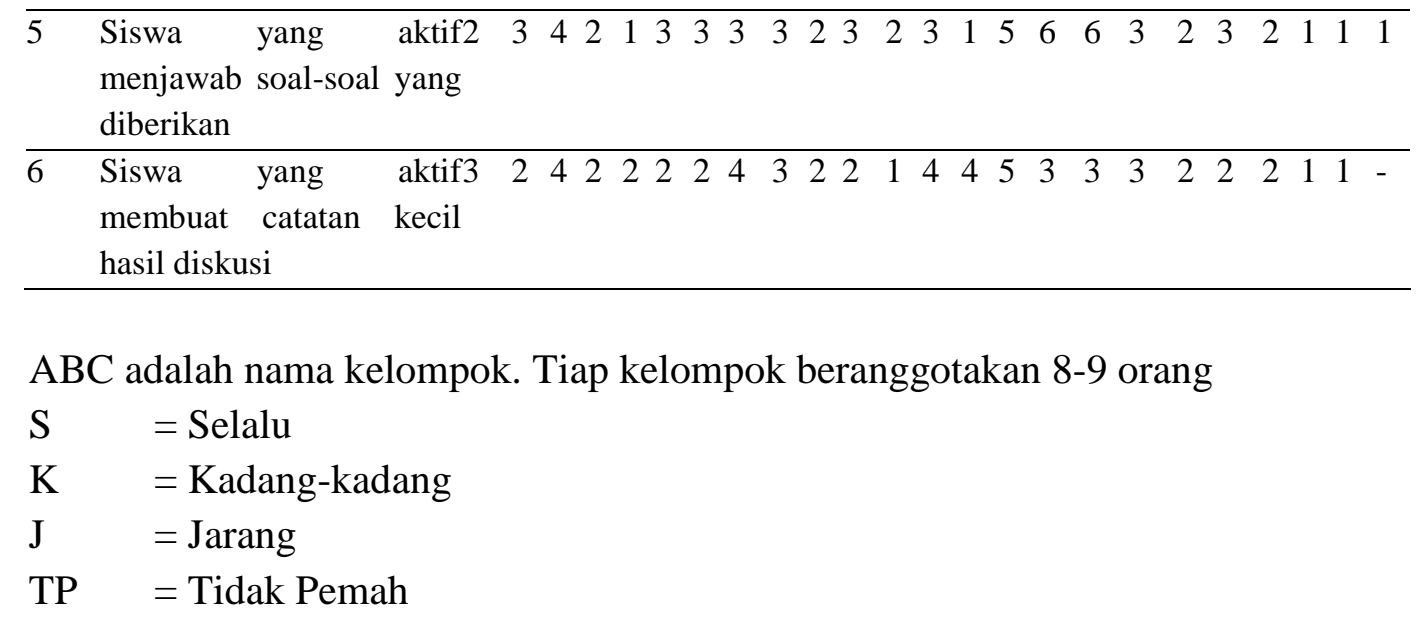

\section{PEMBAHASAN}

Dari hasil penelitian di atas jumlah siswa yang mengikuti remedial mengalami perubahan yang cukup berarti dari pertemuan pertama dan kedua. Hal ini dapat dilihat dari tabel pengamatan tingkah laku siswa. Hal ini kemungkinan siswa sudah mulai menghargai jerih payah teman yang akan membantu mereka memahami konsep bahasa Indonesia tentang mendiskripsikan benda pada siklus pertama, siswa hanya aktif berdiskuasi dengan teman hanya \pm 3 orang dari tiap kelompok atau sekitar 37,50\%, tetapi pada siklus kedua ada kenaikan sehingga rata-rata tiap kelompok yang aktif berdiskusi ada 6 orang tiap kelompok. Sedangkan kenaikan yang cukup signifikan terjadi pada keaktifan siswa dalam menjawab soal-soal yang diberikan dari 3 orang atau 37,50\% pada siklus pertama menjadi $56,67 \%$.

Tabel 5.

Perbandingan Nilai Test Siswa

\begin{tabular}{lll}
\hline Awal & Siklus I & Siklsu II \\
\hline 51,32 & 59,96 & 74,40 \\
\hline
\end{tabular}

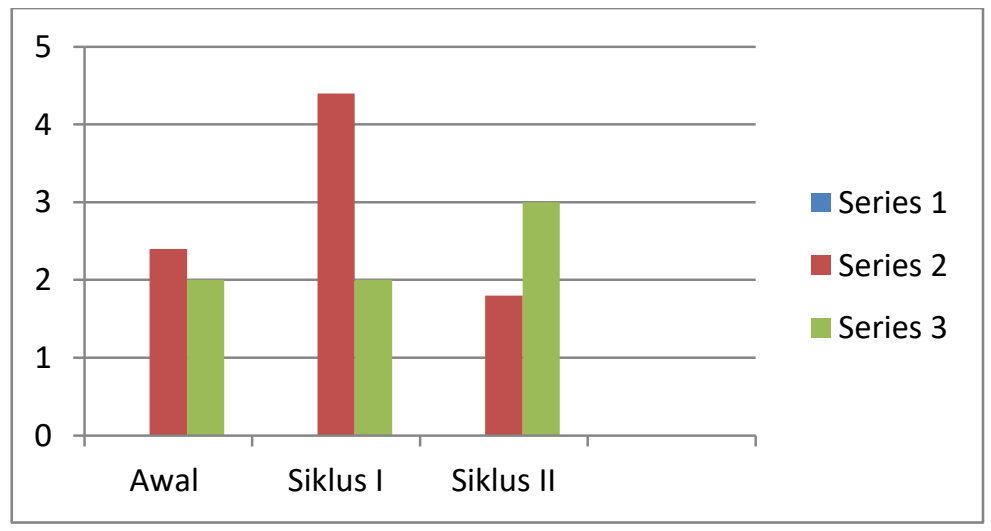

Grafik 1Hasil Belajar Siswa 
Agar seluruh siswa dapat memahami konsep bahasa Indonesia tentang membaca nyaring, maka kegiatan membaca nyaring dengan menggunakan metode demonstrasi dapat menjadi salah satu penunjang keberhasilan siswa. Hal ini dapat dilihat dengan adanya kenaikan yang cukup baik dari awal pada kegiatan siklus pertama dan siklus kedua. Untuk memperoleh hasil yang lebih maksimal mungkin jumlah anggota kelompok dapat diperkecil kendalanya mencari agak sulit karena, jika anggota kelompok diperkecil maka dibutuhkan jumlahnya lebih banyak.

\section{SIMPULAN}

Berdasarkan hasil pengamatan dan pengujian dapat disimpulkan bahwa pembelajaran bahasa Indonesia tentang membaca nyaring dengan menggunakan metode demontrasi dalam kelompok kecil dapat meningkatkan nilai test siswa. Hal ini dapat dilihat dari tabel pengamatan tingkah laku pada saat kegiatan remedial maupun hasil perolehan nilai pada tiap siklusnya. Siswa yang malu atau takut bertanya pada guru ternyata dalam kelompok kecil mereka terlihat tidak malu dan takut bertanya, bahkan terlihat telah aktif baik dalam diskusi maupun dalam hal menjawab soal-soal yang diberikan. Siswa merasa lebih nyaman belajar dalam kelompok kecilnya karena mereka bebas untuk bekerja, belajar sambil bercanda dengan teman-temannya tanpa merasa ada yang akan memarahi, menegur, atau menghukumnya jika mereka berbuat salah. 


\section{DAFTAR PUSTAKA}

Imam, S. (1993). Terampil Berbahasa Indonesia I. Jakarta: Departemen Pendidikan dan Kebudayaan.

Mulyanto, S. (1992). Berbagai Pendekatan dalam Pengajaran Bahasa dan Sastra. Jakarta: Pustaka Sinar Harapan.

Sabarti, A, Maidar G., A, \& Sakura, H. R. (1996). Pembinaan Kemampuan Menulis Bahasa Indonesia.Jakarta: Erlangga.

Sanjaya, W. (2006). Strategi Pembelajaran. Jakarta : Kencana Prenada Media.

Tampubolon. (1990). Kemampuan Membaca, Teknik membaca Efektif dan Efisien. Bandung: Angkasa.

Zuchdi, U. (1997). Pendidikan Bahasa dan Sastra Indonesia di Kelas Rendah.Jakarta : Depdikbud. 